\title{
Mechanical Properties of Apple Skin Are Determined by Epidermis and Hypodermis
}

\author{
Bishnu P. Khanal and Moritz Knoche ${ }^{1}$ \\ Institute for Horticultural Production Systems, Leibniz-University Hannover, \\ Herrenhäuser Straße 2, 30419 Hannover, Germany
}

\begin{abstract}
AdDITIONAL INDEX words. cracking, cuticle, extensibility, fracture, Malus $\times$ domestica, stiffness, strain, stress
Abstract. Mechanical failure of the fruit skin is an early event in the etiology of the disorders russeting and skin spots in a number of apple cultivars including 'Elstar' (Malus $\times$ domestica Borkh.). The objective was to quantify the mechanical properties of excised epidermal segments (ES) of fruit skin and of enzymatically isolated cuticular membranes (CM) using uniaxial tensile tests. ES thickness ranged from 0.25 to $1.8 \mathrm{~mm}$ because thin ES samples of more uniform thickness are difficult to prepare. Sample values for stiffness $(S)$, maximum force $\left(F_{\max }\right)$ and strain at $F_{\max }\left(\varepsilon_{\max }\right)$ were recorded. Measured values were adjusted by regression to refer to a hypothetical standard ES of $0.5 \mathrm{~mm}$ thickness. Generally, $S$ and $F_{\max }$ values were positively related to ES thickness during the preharvest period from 51 to 141 days after full bloom (DAFB) and during the postharvest period from 141 to 259 DAFB in cold storage $\left(1.7^{\circ} \mathrm{C}, 92 \%\right.$ relative humidity). The $\varepsilon_{\max }$ recorded were independent of ES thickness. The $S$ of a standardized ES decreased slightly from 51 to 90 DAFB, then increased up to $161 \mathrm{DAFB}$, and then declined. There were essentially no differences in $S$ recorded for isolated CM and ES. The $F_{\max }$ and $\varepsilon_{\max }$ were highest in young fruit at 51 DAFB but decreased steadily toward harvest and continued to decrease in cold storage after harvest but at a lower rate. The $F_{\max }$ and $\varepsilon_{\max }$ were markedly lower for $\mathrm{CM}$ samples than for ES ones. Monitoring the increased incidence of CM microcracking during a tensile test performed on an ES revealed that CM failure preceded ES failure. The decrease in the $F_{\max }$ for ES during fruit development was accounted for in part by a decrease in the mass of cell wall per unit surface area. Our results show that the epidermal and hypodermal cell layers represent the structural backbone of an apple skin during pre- and postharvest development. Furthermore, CM microcracking has limited relevance to the overall mechanical properties of the skin.
\end{abstract}

Appearance is an important quality attribute in fresh fruit with cosmetic blemishes significantly reducing their value, especially in the premium export market. In apple, commercially relevant examples include the skin disorders russeting (Khanal et al., 2013a) and skin spots (Grimm et al., 2012a). The etiology of both of these disorders involves mechanical failure of the fruit skin with cuticular microcracking being the first detectable symptom (Faust and Shear, 1972a, 1972b; Grimm et al., 2012a). Apples are considered to be susceptible to russeting early in their development (Knoche et al., 2011; Wertheim, 1982), whereas the sensitive period for skin spots is late in development (Grimm et al., 2012a).

A fruit skin is a composite material comprising both cellular and polymeric components. The cuticle is the outermost layer. It is a lipophilic polymer film with cutin and wax as the major constituents (Dominguez et al., 2011a; Heredia, 2003). The cuticle functions as a protective barrier in water transport, gas exchange, and pathogen defense (Dominguez et al., 2011b; Jeffree, 1996; Kerstiens, 1996; Riederer and Schreiber, 2001). The cuticle is deposited on the outer cell wall of the epidermis and also impregnates inner epidermal and, possibly, hypodermal cell walls. In some cases, entire epidermal cells are encased (Meyer, 1944; Miller, 1982). The epidermis is supported by one or several layers of collenchymatous, hypodermal cells (Evert, 2006).

Received for publication 18 Nov. 2013. Accepted for publication 20 Dec. 2013. This research was funded in part by a grant from the Niedersächsisches Ministerium für Wissenschaft und Kultur (grant No. 76251-17-4/09/ZN2543). We thank Friederike Schroeder and Simon Sitzenstock for technical support and Drs. Sandy Lang and Fritz Lenz for very helpful comments on an earlier version of this manuscript.

${ }^{1}$ Corresponding author. E-mail: moritz.knoche@obst.uni-hannover.de.
During growth, the skin composite is subjected to marked strain and stress (Skene, 1982). The cellular components of the skin accommodate the strain by cell division and cell enlargement. In addition, the epidermal and/or hypodermal cells flatten as indicated by increases in their length (periclinal) to thickness (anticlinal) ratio (Maguire, 1998; Meyer, 1944; Tukey and Young, 1942). The situation is more complex for the cuticle polymer that is deposited on these cell layers. In the fruit of some species [e.g., sweet cherry (Prunus avium L.)], cuticle deposition is limited to the early developmental period so that the expansion of the fruit surface later in development causes significant reversible (elastic and viscoelastic) and irreversible (plastic) straining of the skin and even more so of the cuticle (Grimm et al., 2012b; Knoche et al., 2004; Knoche and Peschel, 2006). In apple, however, the pattern is different. Throughout fruit development, cuticle material is deposited as the area of the skin surface expands with no apparent buildup of reversible elastic strain (Khanal et al., 2013a, 2013b). Nevertheless, micrographs from scanning electron microscopy (SEM) of apple fruit surfaces often reveal a network of fine cuticular cracks, even in the absence of any russeting (Curry, 2012; Faust and Shear, 1972b; Maguire et al., 1999; Roy et al., 1999). Whether these cracks are mechanically relevant in the development of fruit surface disorders is not yet known. These observations suggest that 1) the appearance of a fruit is closely related to the mechanical properties of its skin; 2) surface area expansion subjects the fruit skin to marked strain; and 3) maintenance of skin integrity is essential if the fruit is to remain blemish-free. Considering the importance of these relationships, surprisingly little is known about the mechanical properties of apple skin. 
The objective of this study was to quantify the mechanical properties of the skin (cuticle, epidermis, and hypodermis) of developing and cold-stored apple fruit. We used excised skin samples of developing and cold-stored 'Elstar' apples as a model system because 1) 'Elstar' is susceptible to both russeting and skin spots; 2) susceptibility to both disorders changes in the course of fruit development; and 3) mechanical failure of the skin is considered to be the first detectable symptom in both disorders (Faust and Shear, 1972a, 1972b; Grimm et al., 2012a).

\section{Materials and Methods}

Plant materials. Fruit of 'Elstar' apples were randomly sampled from the block of 50 trees (two to three fruit per tree per side of row) grafted on 'M.9' rootstocks growing in an experimental orchard of the Leibniz University at Sarstedt, Germany (lat. 52 $14^{\prime} \mathrm{N}$, long. $9^{\circ} 49^{\prime} \mathrm{E}$ ) and managed according to the European Union regulations for integrated fruit production. Fruit were sampled periodically from $51 \mathrm{~d}$ after full bloom (DAFB) onward. At this stage, fruit diameter averaged $\approx 40 \mathrm{~mm}$, which is the minimum size needed for preparation of epidermal segments (ES) of the fruit skin for tensile testing. At 141 DAFB when fruit were commercially mature, all fruit were harvested and put into cold storage $\left[1.7{ }^{\circ} \mathrm{C}\right.$, 92\% relative humidity $(\mathrm{RH})$ ] for up to $118 \mathrm{~d}$ (equivalent to $259 \mathrm{DAFB})$. At selected time intervals, fruit were picked in the field, transferred to the laboratory, and either processed fresh or held at $2{ }^{\circ} \mathrm{C}$ for no longer than $24 \mathrm{~h}$. Fruit sampled from storage were always processed on the day of sampling.

Preparation of ES and isolation of CM. Preliminary experiments established that the mechanical properties of ES did not differ when excised in longitudinal \{i.e., parallel to the calyx/pedicel axis [maximum force $\left(F_{\max }\right) 2.8 \pm 0.1 \mathrm{~N}$, strain at $F_{\max }\left(\varepsilon_{\max }\right) 11.5 \% \pm 0.6 \%($ mean $\left.\left.\pm \mathrm{SE})\right]\right\}$ or latitudinal direction [i.e., perpendicular to the calyx/pedicel axis $\left(F_{\max } 2.7 \pm 0.2 \mathrm{~N}\right.$, $\left.\left.\varepsilon_{\max } 12.4 \% \pm 0.5 \%\right)\right]$. Thus, the ES were judged to be isotropic in the plane of the fruit surface (B.P. Khanal, unpublished data). The $\varepsilon_{\max }$ for ES from the blush surface were $11.0 \% \pm 0.4 \%$ at an $F_{\text {max }}$ of $2.6 \pm 0.1 \mathrm{~N}$, whereas the same values for the non-blush surface were $10.8 \% \pm 0.5 \%$ (similar) and $2.1 \pm 0.1 \mathrm{~N}$ (lower). To minimize variation, ES were always excised longitudinally from the non-blush surface. Because of its reduced curvature, ES were taken from the equatorial region using a custom-made punch that produces a biconcave (dumbbell-shaped) specimen with 4.25-mm waist width and 30- to 40-mm length. Because we found it impossible to reproducibly prepare thin ES of preset thickness, ES of varying thickness were cut using a razor blade. ES thickness was subsequently determined by image analysis (software package Cell-P; Olympus Europa, Hamburg, Germany) from calibrated images prepared under a binocular microscope. To minimize artifacts resulting from transpiration of the ES, tensile tests were performed and completed within 3 min of excision and preparation of the ES.

Cuticular membranes were isolated from ES excised as described previously by incubating in $50 \mathrm{~mm}$ citric acid buffer solution $\left(\mathrm{pH}\right.$ 4.0) containing $90 \mathrm{~mL} \cdot \mathrm{L}^{-1}$ pectinase (Panzym Super E flüssig; Novozymes, Bagsvaerd, Denmark), $5 \mathrm{~mL} \cdot \mathrm{L}^{-1}$ cellulase (Cellubrix L; Novozymes), and $\mathrm{NaN}_{3}$ at $30 \mathrm{~mm}$ (Orgell, 1955; Yamada et al., 1964). The isolation medium was refreshed periodically until the CMs separated from adhering cell layers. CMs were thoroughly rinsed with deionized

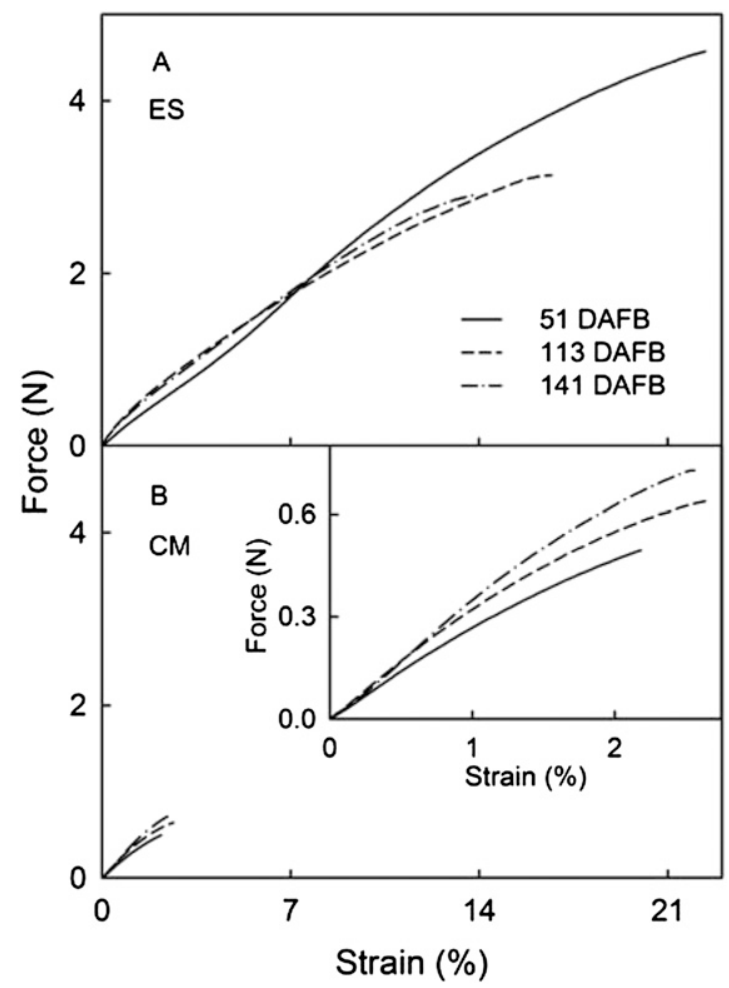

Fig. 1. Representative force/strain diagrams of excised epidermal segments (ES) of the fruit skin (A) and of enzymatically isolated cuticular membranes (CM) (B) subjected to uniaxial tensile tests. Force/strain diagram of CM redrawn at a different scale [B (inset)]. ES were excised in the longitudinal direction, parallel to the pedicel-calyx axis, from the equatorial region of 'Elstar' apple fruit at 51, 113, and $141 \mathrm{~d}$ after full bloom (DAFB).

water, dried at room temperature, and stored under laboratory conditions $\left(\approx 22^{\circ} \mathrm{C}, 50 \% \mathrm{RH}\right)$.

Tensile TEST. Without further handling, ES were mounted between the clamps of a material testing machine ( $Z 0.5$ and KAP-TC 50-N force transducer; Zwick/Roell, Ulm, Germany). The isolated CMs were mounted in a frame of paper and masking tape to prevent unintentional strain and damage during handling. The frames with CM strips were hydrated by incubating in deionized water for $16 \mathrm{~h}$ and thereafter mounted between the clamps of the material testing machine $(Z 0.5)$. The distance between the clamps corresponding to the free length of the specimen was $16 \mathrm{~mm}$ with the position of the waist arranged in the center between the clamps. An uniaxial tensile force was applied at a constant strain rate of $3 \mathrm{~mm} \cdot \mathrm{min}^{-1}$ until failure of the ES or CM. Applied force and crosshead travel (in millimeters) were recorded and maximum force $F_{\max }$ (in Newtons) and travel at $F_{\max }$ (in millimeters) were extracted from the data and the strain at $F_{\max }\left(\varepsilon_{\max }\right)$ was calculated (Khanal et al., 2013a). Stiffness ( $S$ in Newtons) was calculated as the maximum slope of the force (Newtons) vs. fractional strain (in percent per 100) relationship. Like the commonly used modulus of elasticity in material science [ $E$ (in megapascals)], this $S$ is a measure of the elasticity of the sample. However, unlike $E, S$ reflects the properties of the specimens as excised from the surface because it is not corrected for differences in sample thickness and hence sample cross-sectional area. Furthermore, a meaningful comparison of $E$ would assume isotropic properties of the specimen in all three dimensions. Tensile tests were carried out at $\approx 22{ }^{\circ} \mathrm{C}$ 


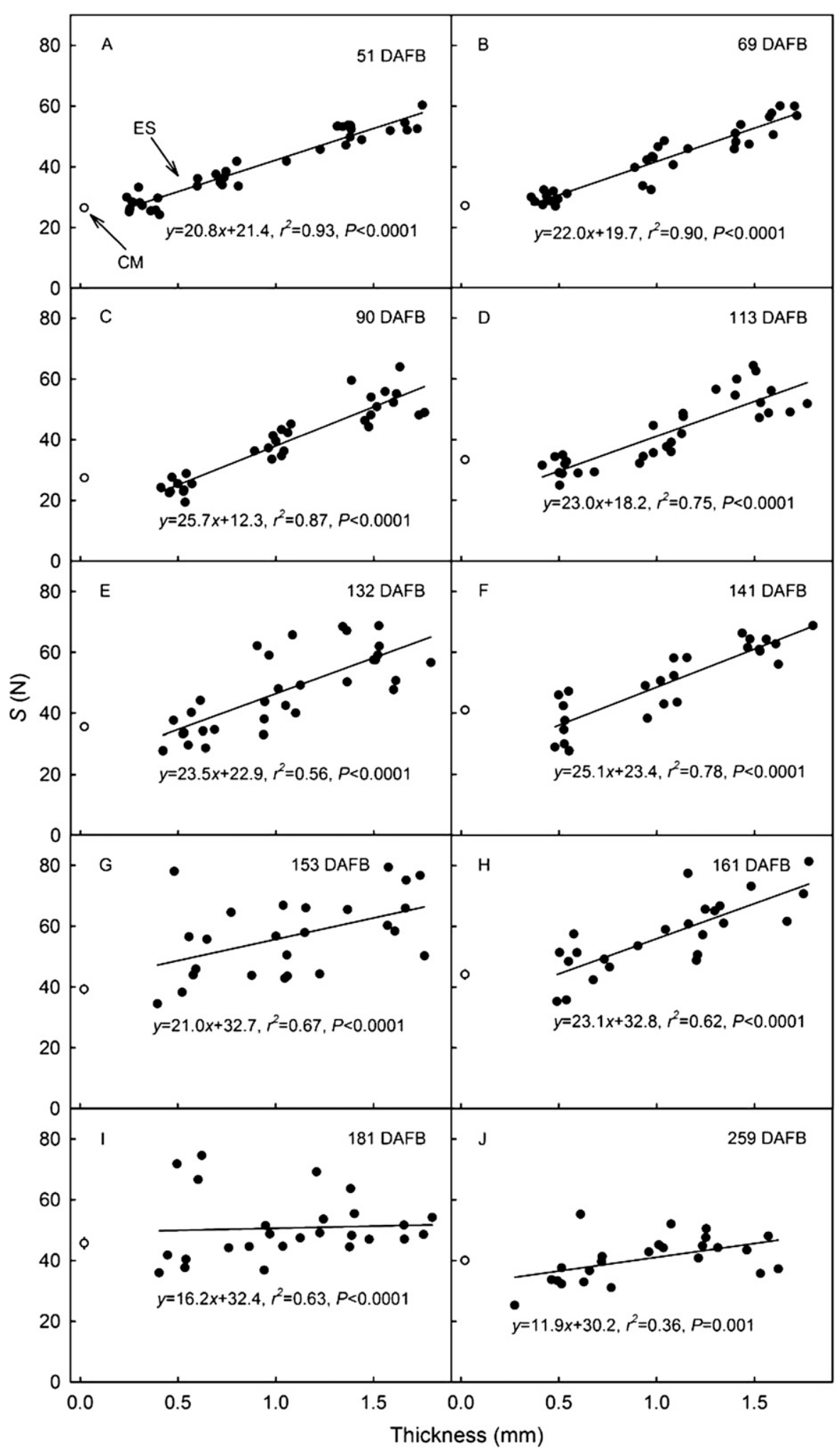

Fig. 2. Stiffness $(S)$ of excised epidermal segments (ES) of the fruit skin as a function of their thickness (closed symbols) and of enzymatically isolated cuticular membrane [CM (open symbols)] at various developmental stages of 'Elstar' apple (A-F) and various durations of cold storage $\left(1.7^{\circ} \mathrm{C}, 92 \%\right.$ relative humidity) after harvest (G-J). Fruit were harvested at $141 \mathrm{~d}$ after full bloom (DAFB). The values of $S$ of the CM are the means $( \pm \mathrm{sE}, \mathrm{n}=$ 10). For ES data point represent individual observations. and $50 \%$ RH on a 23 to 36 ESs and $10 \mathrm{CMs}$ per sampling date. For data analysis, the $S, F_{\max }$, and $\varepsilon_{\max }$ derived for each ES on a given sampling date were plotted against thickness of the same ES and a regression line fitted (see Fig. 1 for an example for $\left.F_{\max }\right)$. From these regression equations, the hypothetical $S, F_{\max }$, and $\varepsilon_{\max }$ for a standard ES of constant thickness of $0.5 \mathrm{~mm}$ were calculated and compared through the course of fruit development and subsequent storage (see Fig. 3 for an example). This procedure avoids extrapolation beyond the thickness ranges investigated.

M O N I T O R I N G OF C M MICROCRACKING DURING TENSILE TESTING. ES samples of $\approx 0.5 \mathrm{~mm}$ thickness were prepared as described previously, mounted in the material testing machine, and subjected to increasing tensile force up to $2.3 \mathrm{~N}$. This tensile force represents $0.75 \times F_{\max }$ of the specimens $\left(F_{\max } 3.1 \mathrm{~N}\right)$ determined earlier on samples from the same batch of fruit. When $0.75 \times F_{\max }$ was reached, the force was held constant ("hold period"), whereas the strain continued to increase. To avoid failure of the ES as a consequence of creep, strain was held constant when $\varepsilon$ reached $\approx 11 \%$, which represents approximately $0.85 \times \varepsilon_{\max }$ of the specimen $\left(\varepsilon_{\max }\right.$ $13 \%)$. Two $2-\mu \mathrm{L}$ droplets of $0.1 \%$ aqueous acridine orange fluorescent dye were placed on the outer surface of the strained ES immediately after the beginning of the hold period. Droplets were allowed to rest on the ES for $10 \mathrm{~min}$ and were then carefully removed by blotting with soft tissue paper. At this time, the stained ES were allowed to relax again, removed from the testing machine, positioned in a petri dish, and observed using a fluorescence microscope (MZ10F; Leica Microsystems, Wetzlar, Germany). Calibrated images were prepared (camera DP 71, Olympus Europa) and the dyeinfiltrated area was quantified over a representative fraction $\left(3 \mathrm{~mm}^{2}\right)$ of the dye droplet contact area using image analysis (software package Cell-P). ES prepared in the same manner, treated with dye solution, but not subjected to tensile forces served as control $(n=15)$. 


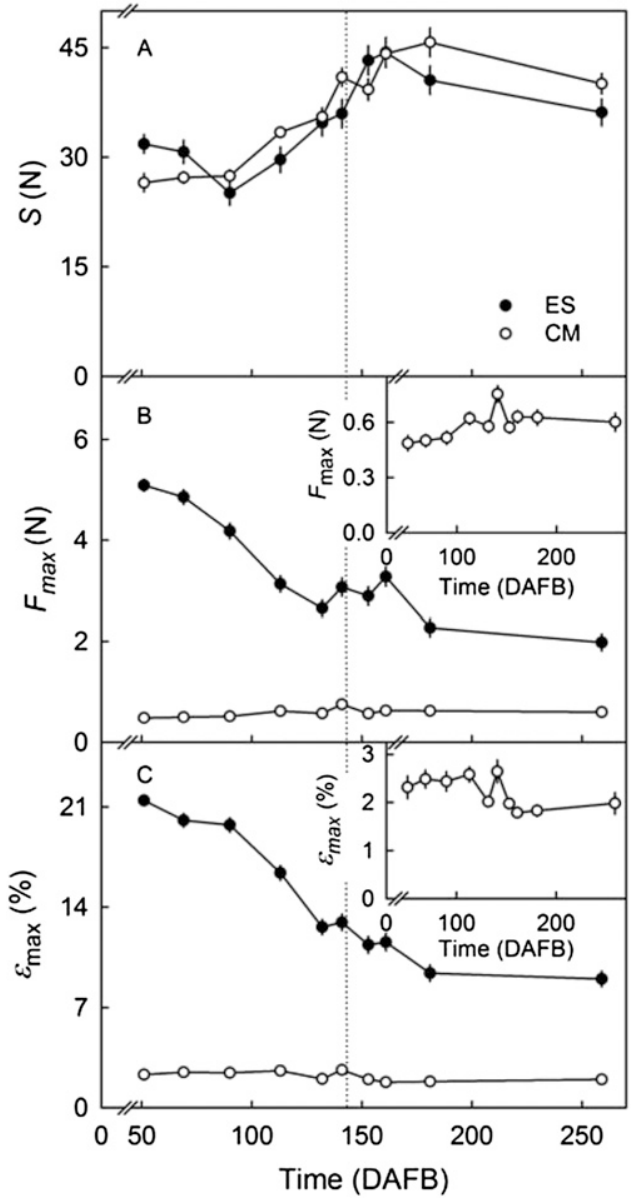

Fig. 3. Developmental time course of change in stiffness $(S)(\mathbf{A})$, maximum force $\left(F_{\max }\right)(\mathbf{B})$ and strain at $F_{\max }\left(\varepsilon_{\max }\right)(\mathbf{C})$ of excised epidermal segments (ES) of the fruit skin and enzymatically isolated cuticular membranes (CM) of developing, mature, and stored 'Elstar' apple fruit. $F_{\max }$ [B (inset)] and $\varepsilon_{\max }$ [C (inset)] of the $\mathrm{CM}$ as a function of time redrawn to a different scale. Fruit were harvested at $141 \mathrm{~d}$ after full bloom (DAFB), indicated by the vertical dotted line, and cold-stored $\left(1.7^{\circ} \mathrm{C}, 92 \%\right.$ relative humidity). The values of $S$, $F_{\max }$, and $\varepsilon_{\max }$ of the $\mathrm{CM}$ are the means $( \pm \mathrm{SE}, \mathrm{n}=10)$. For the ES, the values (means $\pm \mathrm{SE}$ ) of $S, F_{\max }$, and $\varepsilon_{\max }$ were calculated for a hypothetical ES of $0.5 \mathrm{~mm}$ standard thickness using regression equations describing the relationships between $S$ or $F_{\max }$ or $\varepsilon_{\max }$ and ES thickness $(\mathrm{n}=23$ to 36$)$. For more detail see the "Materials and Methods" section.

Quantifying Cell-wall Mass. To establish potential relationships between the amount of cell wall adhering to an ES and its mechanical properties, the mass of cell wall per unit area of ES was quantified after the mechanical test. Briefly, the surface of the fractured ES strip was photographed (camera DP 71) under a dissecting microscope (MZ6; Leica Microsystems) and the area quantified by image analysis (software package Cell-P). ES were then dried at $70^{\circ} \mathrm{C}$, weighed, incubated in the enzyme solution used for CM isolation as described previously, and their CM isolated. The epidermis of 'Elstar' apple has irregular-shaped cells and some hypodermal development of the CM. However, epidermal cells are only occasionally encased in the CM (B.P. Khanal, unpublished data). Thus, these cells will be largely accessible for the enzyme solution. After isolation, CMs were then thoroughly rinsed, dried, and reweighed. The mass of cell wall per unit surface area was calculated as the difference between the dry weight of the
ES and that of the CM divided by the area of the ES $(n=8$ to 12$)$.

Compression TEST. To quantify the softening of fruit during cold storage, tissue cylinders of parenchyma $(15 \mathrm{~mm}$ diameter, $10 \mathrm{~mm}$ height) were prepared at regular time intervals from the same batches of apples used in the tensile tests. The length axis of these cylinders was orientated tangentially relative to the fruit surface. Within 3 min of preparation, the cylinders were subjected to a compression test between two parallel plates using a material testing machine $(Z 0.5$ and KAF-TC 500-N force transducer; Zwick/Roell). The rate of compression was $3 \mathrm{~mm} \cdot \mathrm{min}^{-1}$. Samples were compressed up to the failure point as indicated by a sudden drop in force. The force at failure $\left[F_{\max }\right.$ (in Newtons) $]$ was recorded and the failure stress $\left[\sigma_{\max }\right.$ (in megapascals)] calculated by dividing $F_{\max }$ by the cross-sectional area of the tissue cylinder $(\mathrm{n}=10)$.

Measurement of Cell dimensions. Tissue blocks $(5 \times 5 \mathrm{~mm}$, $1 \mathrm{~mm}$ thick) were excised from young (51 DAFB) and mature fruit (141 DAFB) with their $5 \times 5$-mm face oriented in anticlinal longitudinal (i.e., parallel to the calyx/pedicel axis) or in anticlinal latitudinal (i.e., perpendicular to the calyx/pedicel axis) directions using a razor blade. Cell walls were stained by incubating sections in $0.1 \%(\mathrm{w} / \mathrm{v})$ aqueous calcofluor white (Fluorescent Brightener 28; Sigma-Aldrich, Steinheim, Germany) for 2 to $5 \mathrm{~min}$. Skin sections were removed from the dye solution, rinsed with deionized water, positioned on a microscope slide, and viewed at $\times 10$ under a fluorescence microscope (BX-60; Olympus Europa). Calibrated images of fruit skin cross-section were taken (camera DP 71) and dimensions of cells analyzed by image analysis (software package Cell-P). Periclinal (parallel to the surface) and anticlinal (perpendicular to the surface) diameters and the distance of the cells from the surface were quantified. Cross-sectional areas of cells were calculated assuming an elliptical shape, the aspect ratios were obtained by dividing the periclinal cell diameter by the respective anticlinal diameter. A minimum of 10 cells was measured on one image per section from a total of 10 fruit.

Data ANALYSIS AND PRESENTATion. Values in Figures 3 and 7 and for the CM in all other figures are presented as means and SEMS. Where error bars are not shown in figures, they were smaller than data symbols. In all other figures the points represent individual ES. Data were subjected to analysis of variance [ANOVA (Proc ANOVA or GLM)] or linear regression analysis (Proc REG) using SAS (Version 9.1.3; SAS Institute, Cary, NC). Percentage strain data were arcsine-transformed before ANOVA. Means were compared using Tukey's Studentized range test $(P<0.05)$.

\section{Results}

The force vs. strain diagrams for ES and CM obtained in uniaxial tensile tests of specimens of all three sampling dates were essentially linear up to $\approx 70 \%$ of $\varepsilon_{\max }$ (Fig. $1 \mathrm{~A}-\mathrm{B}$ ). At higher strains, slopes of the force strain diagrams slightly decreased. No discontinuities were apparent in the force vs. strain diagrams for fruit skin at any sampling time.

The values of $S$ of the ES were positively, linearly, and significantly related to ES thickness throughout development (Fig. 2A-F) and (after harvest) during the early storage period 


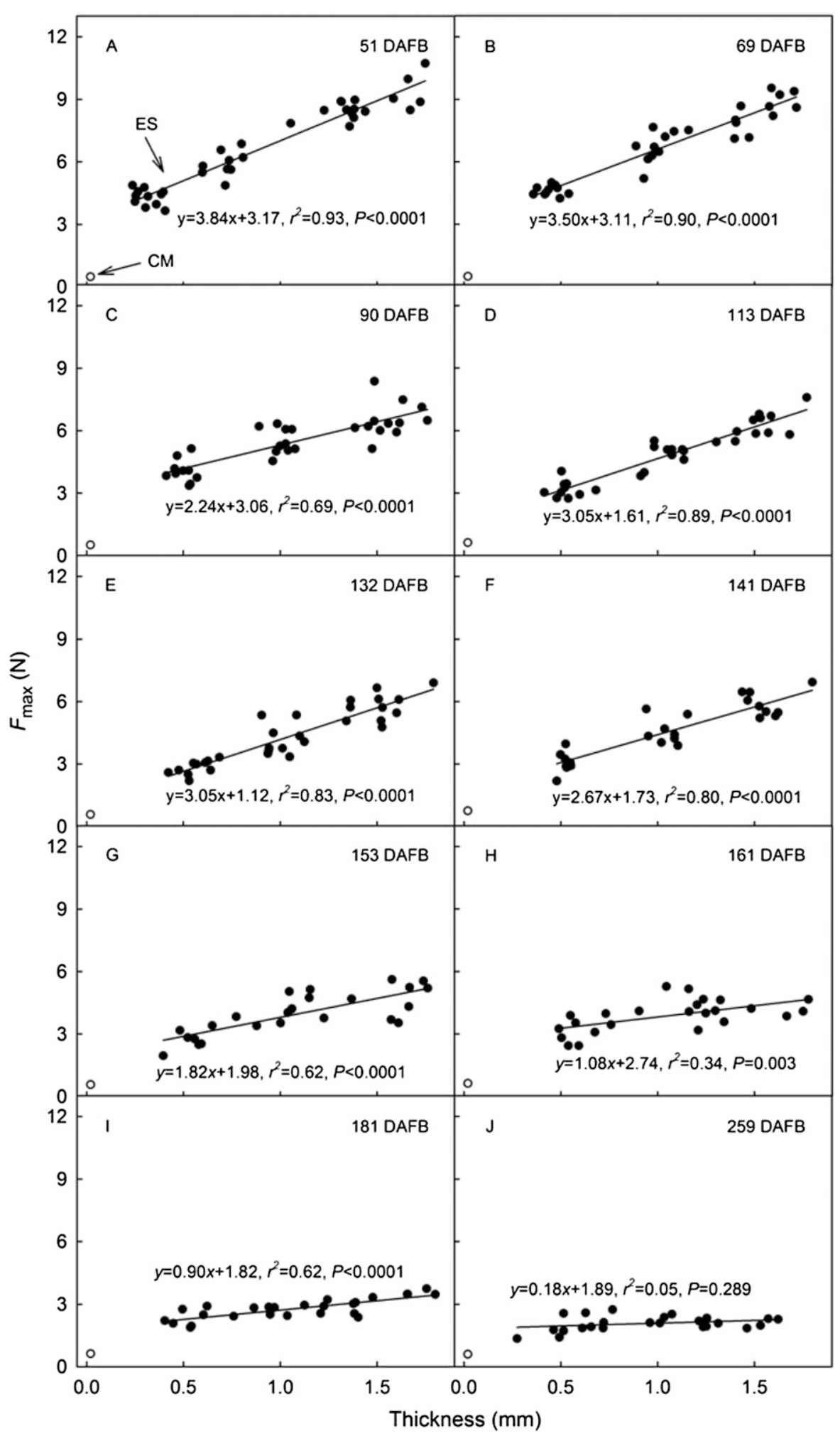

Fig. 4. Maximum force $\left(F_{\max }\right)$ of excised epidermal segments (ES) of the fruit skin as a function of their thickness (closed symbols) and enzymatically isolated cuticular membrane [CM (open symbols)] at various stages of development $(\mathbf{A}-\mathbf{F})$ and various durations of cold storage $\left(1.7{ }^{\circ} \mathrm{C}, 92 \%\right.$ relative humidity) of 'Elstar' apple after harvest (G-J). Fruit were harvested at $141 \mathrm{~d}$ after full bloom (DAFB). The values of $F_{\max }$ of the $\mathrm{CM}$ are the means $( \pm \mathrm{SE}, \mathrm{n}=10)$. For ES data point represent individual observations.
(Fig. 2G-H). There was little difference in slope among these relationships. In contrast, during the later phase of storage (i.e., at 181 and 259 DAFB), dependence of $S$ on thickness decreased and essentially disappeared (Fig. 2I-J). Calculating the value of $S$ for a standard ES of $0.5-\mathrm{mm}$ thickness revealed that it decreased over the period 51 to 90 $\mathrm{DAFB}$, then increased up to 161 DAFB, and reached a maximum around the time of harvest before decreasing again thereafter (Fig. $3 \mathrm{~A}$ ). The $S$ of the isolated CM was similar to the $S$ of the thinnest ES investigated (Fig. 2A-F). Furthermore, the value of $S$ for the CM followed a similar temporal pattern as for the ES (Fig. 3A).

The $F_{\max }$ of ES increased linearly with ES thickness at all stages of development (Fig. 4A-F). The slope of the regression line of $F_{\max }$ vs. thickness remained essentially constant during the preharvest period except for at the 90 DAFB sampling, where the slope was somewhat smaller. However, during subsequent storage, the slope of the regression lines decreased consistently from $1.8 \pm 0.3$ at 153 DAFB to essentially zero at 259 DAFB (Fig. 4G-J). Calculating the $F_{\max }$ of a standard ES $(0.5 \mathrm{~mm}$ thick) revealed that $F_{\max }$ decreased continuously up to approximately maturity. With some variation, the decrease in $F_{\max }$ continued in storage at a reduced rate until 259 DAFB (Fig. 3B). The $F_{\max }$ of the $\mathrm{CM}$ was always markedly lower than that of the standard ES. It increased slightly during development and remained about constant during cold storage [Fig. 3B (inset)].

The $\varepsilon_{\max }$ was largely independent of the thickness of the ES at all stages of development and throughout the postharvest period as indicated by the consistently low coefficients of determination that only occasionally were significant (Fig. 5A-J). The calculated $\varepsilon_{\max }$ of an ES of standard thickness $(0.5 \mathrm{~mm}$ thick) decreased consistently during development, throughout maturation into the postharvest phase (up to $181 \mathrm{DAFB}$ ), and then remained constant (Fig. 3C). In contrast, the $\varepsilon_{\max }$ of the CM was always markedly lower than that of ES. It was 


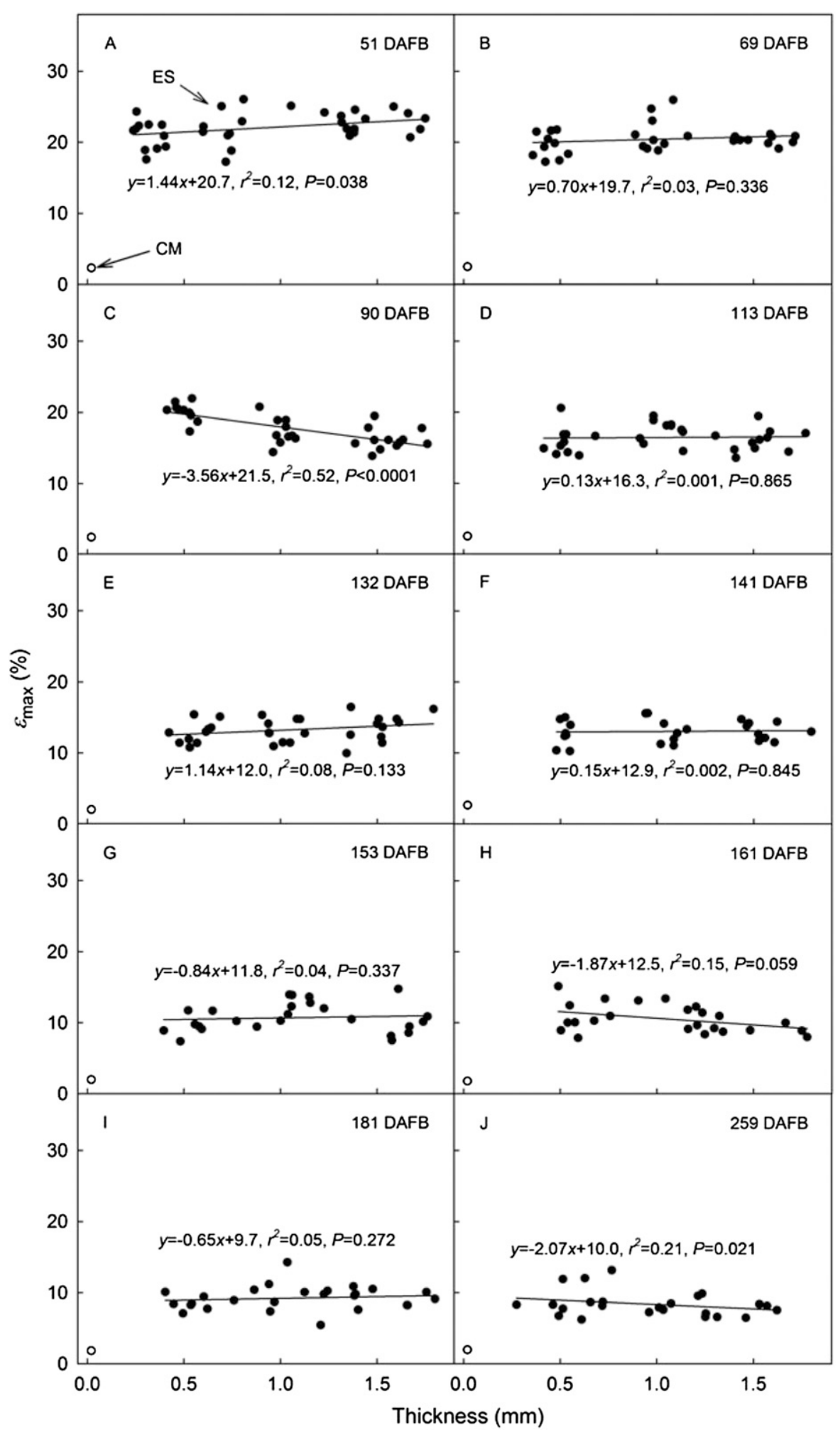

Fig. 5. Strain at maximum force $\left(\varepsilon_{\max }\right)$ of excised epidermal segments (ES) of the fruit skin as a function of thickness (closed symbols) and of enzymatically isolated cuticular membrane [CM (open symbols)] at various stages of development (A-F) and after various durations of cold storage $\left(1.7{ }^{\circ} \mathrm{C}, 92 \%\right.$ relative humidity) after harvest (G-J). 'Elstar' apple fruit were harvested at $141 \mathrm{~d}$ after full bloom (DAFB). The values of $\varepsilon_{\max }$ of the $\mathrm{CM}$ are the means $( \pm \mathrm{SE}, \mathrm{n}=10$ ). For ES data point represent individual observations. constant throughout development, decreased slightly at harvest, and remained constant again during storage [Fig. 3C (inset)].

Fluorescence microscopy of ES subjected to $0.75 \times F_{\max }$ revealed that the frequency of infiltrated microcracks in the $\mathrm{CM}$ of the strained ES increased markedly compared with the unstrained controls (Fig. 6). The percentages of area infiltrated by acridine orange averaged $33.1 \% \pm 5.0 \%$ and $0.5 \% \pm$ $0.2 \%$ for strained vs. non-strained ES, respectively. The microcracks on the strained ES were oriented perpendicular to the direction of the applied force (Fig. 6A).

The mass of cell wall material per unit fruit surface area of a standard ES of 0.5-mm thickness decreased linearly throughout development until harvest and remained approximately constant during storage (Fig. 7A). Plotting the mass of cell wall material vs. the $F_{\text {max }}$ of the ES revealed a significant and positive relationship for developing fruit where the mass of cell wall material accounted for $57 \%$ of the variation in $F_{\max }$ (Fig. 7B). In contrast, the mass of CM per unit surface area increased up to approximately harvest and then remained constant [Fig. 7A (inset)]. There was no significant relationship between the mass of CM and its $F_{\max }$ [Fig. 7B (inset)]. The $F_{\text {max }}$ of parenchyma decreased continuously during the storage period (Fig. 7C).

The cross-sectional area of the skin cells increased continuously from epidermis to hypodermis and into the parenchyma (Figs. 8A and $8 \mathrm{C})$. There were no significant differences in cell cross-sectional areas when sectioned in longitudinal and latitudinal planes either in young or mature fruit. The hypodermal and parenchyma cells of mature fruit were somewhat larger than those of young fruit (Figs. 8A and 8C). The aspect ratios of cells of young fruit increased from epidermis into the hypodermis (down to approximately a $100-\mu \mathrm{m}$ depth from the surface) but then decreased further into the hypodermis and in the underlying parenchyma tissue (Fig. 8B). In contrast, in mature fruit, aspect ratios of epidermal and hypodermal 


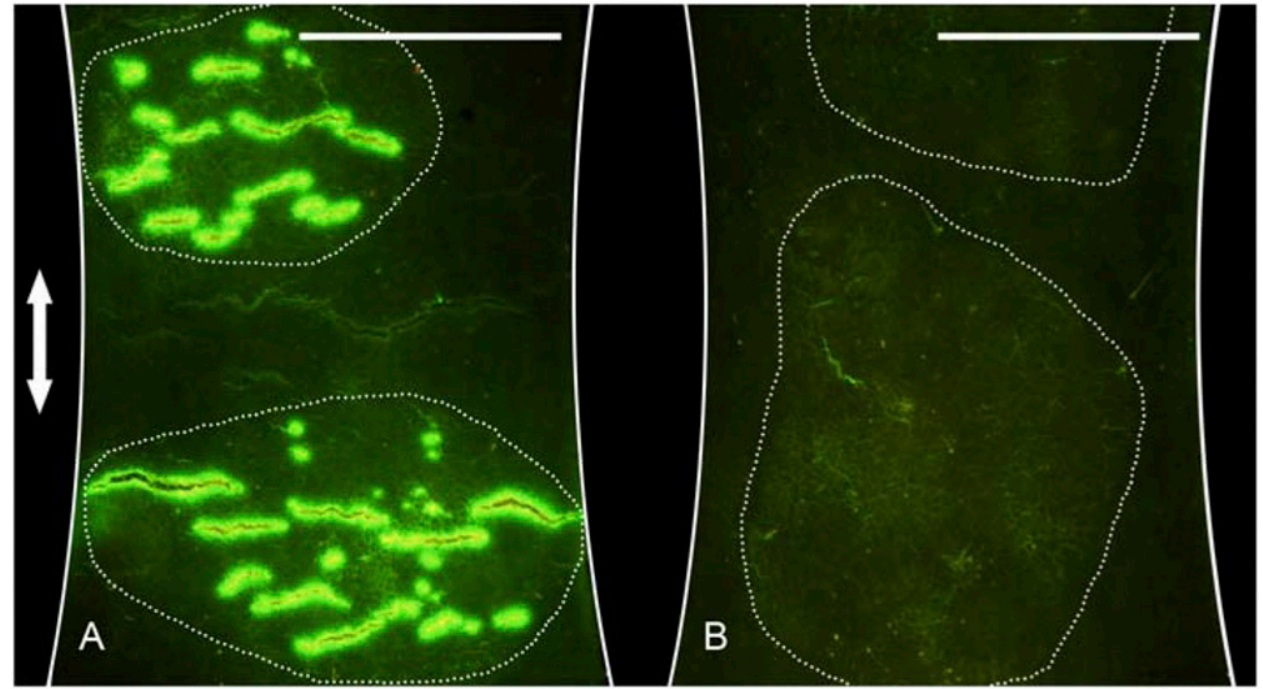

Fig. 6. Fluorescence micrographs of the surface of excised epidermal segments (ES) of the fruit skin of 'Elstar' apple. (A) ES subjected to a tensile force equivalent to $0.75 \times F_{\max }$ of the specimen. (B) Same as in $\mathbf{A}$, but the ES not subjected to tensile forces. White lines show contour of the waist region of dumbbellshaped specimens. The dotted lines show the footprints of the acridine orange droplets $(2 \mu \mathrm{L})$ applied to the ES surface during the hold period of the tensile test. Arrow indicates the direction of the applied force ( scale bars $=2 \mathrm{~mm}$ ).

cells were highly variable and decreased as the distance from the surface increased (Figs. 8B and 8D). There was no consistent difference in the aspect ratios of cells in longitudinal and in latitudinal planes, either in young or mature fruit (Figs. 8B and $8 \mathrm{D})$.

\section{Discussion}

The results presented provide several new and important findings: 1) epidermis and hypodermis represent the mechanical "backbone" of the skin of apple fruit, whereas the mechanical contribution made by the cuticle is small or negligible; 2) the mechanical properties of the skin $\left(S, F_{\max }\right.$, and $\varepsilon_{\max }$ ) change markedly during preharvest development and, to a lesser extent, during postharvest cold storage; and 3) the $\varepsilon_{\max }$ of the CM is markedly lower than that of the ES and, therefore, the CM inevitably fails first in response to straining of the skin. This failure results in the formation of microcracks. However, CM failure has no significant mechanical relevance to the overall mechanical properties of the skin composite.

EPIDERMIS AND HYPODERMIS AS THE STRUCTURAL BACKBONE OF THE FRUIT SKIN. That the epidermal and hypodermal cell layers represent the structural backbone as indexed by the $F_{\max }$ of the fruit skin is inferred from the following observations: 1) the $F_{\max }$ of a standard 0.5 -mm-thick ES was 3- to 10 -fold higher than the $F_{\max }$ of the $\mathrm{CM} ; 2$ ) monitoring the formation of microcracks during a tensile test clearly indicates that the $\mathrm{CM}$ fails before the underlying cell layers (epidermis, hypodermis, and parenchyma); 3 ) the $F_{\max }$ of the fruit skin was significantly and positively related to the mass of the cell wall material of the ES. This would be as expected if the cellulosic cell walls were the primary load-bearing structures (Chanliaud et al., 2002; Vincent, 1990, 1999). In fact, the mechanical properties of the CM polymer are expected to be related to the amount of cellulose that remains in the $\mathrm{CM}$ after enzymatic isolation (Lopez-Casado et al., 2007); 4) microscopic analysis of crosssections of the fruit skin revealed that the aspect ratios of the epidermal and hypodermal cells are larger than those of the parenchyma cells. This suggests that larger strains occurred in the epidermal and hypodermal cell layers than in the parenchyma; and 5) the epidermis and hypodermis are collenchymatous as indexed by their thick cell walls (Evert, 2006) suggesting that these layers are to some extent structured to resist mechanical stress. That the contribution of parenchyma to the mechanical characteristics of the whole is small compared with that of the epidermal and hypodermal cell layers is also inferred from the positive y-axis intercepts of the regressions lines relating $F_{\max }$ to ES thickness. Also, the slopes of the regression lines are low indicating that varying the thicknesses of the parenchyma in the ES have only small effects on $F_{\max }$. The epidermal and hypodermal cell layers make up $\approx 300 \mu \mathrm{m}$ of the skin thickness in a mature 'Elstar' apple (B.P. Khanal, unpublished data). Unfortunately, it is technically impossible to excise ES samples comprising intact epidermis and hypodermis but containing no parenchyma at all. However, from the relationships obtained between $F_{\max }$ and ES thickness, we can estimate the $F_{\max }$ of a hypothetical $300-\mu \mathrm{m}$-thick ES at $2.5 \mathrm{~N}$. This is $83 \%$ of the measured $F_{\max }$ of a $500-\mu \mathrm{m}$-thick $(0.5 \mathrm{~mm})$ ES. It is reasonable to infer that the remaining $17 \%$ of the $F_{\max }$ value was accounted for by a $200-\mu \mathrm{m}$ thickness of adhering parenchyma. This calculation also reveals that the $F_{\max }$ of a $300-\mu m$-thick ES exceeds that of an isolated CM by a factor of $\approx 3.4$.

Change in Properties throughout Development. During fruit development, the surface area of the skin expands, subjecting it to tangential tensile forces. These forces bring about a continuous increase in strain that becomes constant only at harvest. Skin properties are also subject to continuous change resulting from ongoing cell division and enlargement, the deposition of new cell-wall material, and changes that occur within the cell wall as a result of the activity of cell-wall-modifying enzymes such as expansins, cellulases, and pectinases. The latter are particularly active during the postharvest period. One or, more likely, several of these processes must account for the observed developmental changes in the rheological properties of apple fruit skins.

The developmental increases in $S$ and decreases in $\varepsilon_{\max }$ and $F_{\max }$ may be consequences of increasing strain in the skin during growth. Because there was essentially no relaxation of the fruit skin on excision [grand mean 5\% (B.P. Khanal, unpublished data)], any growth strain of the ES must have been irreversible and maintained when ES were excised and 

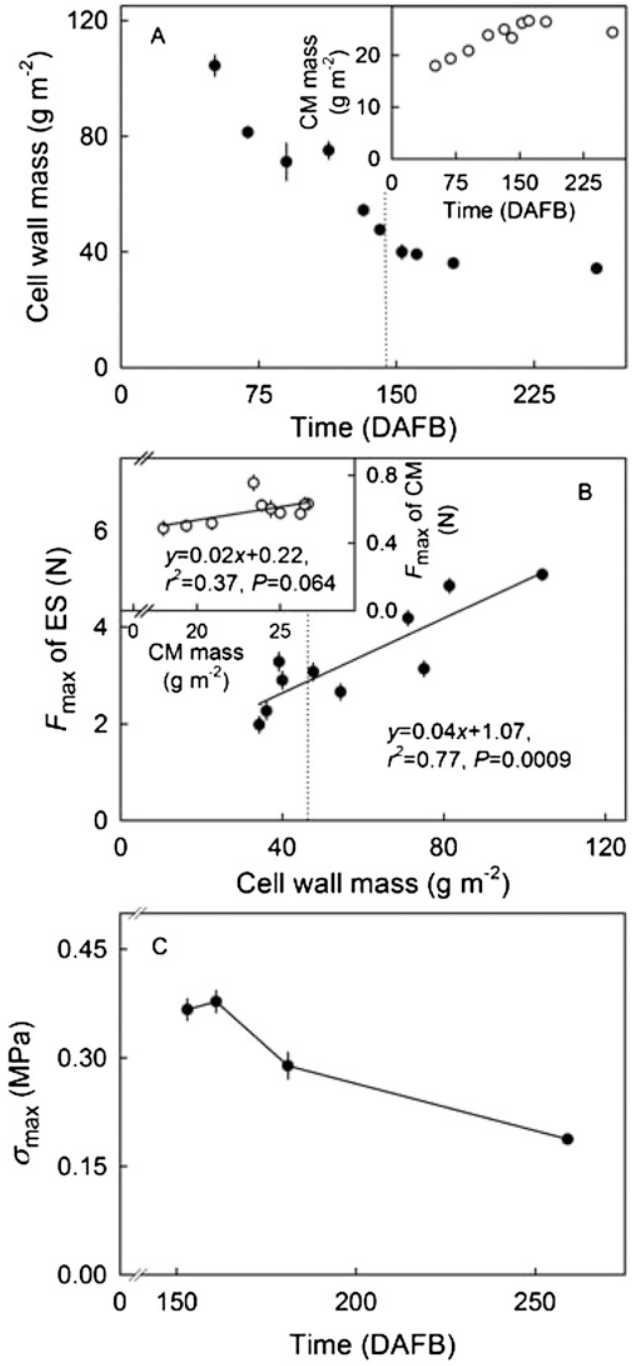

Fig. 7. (A) Time course of change in the mass of cell walls per unit surface area of excised epidermal segments (ES) of the fruit skin of 'Elstar' apple (A) and in the mass per unit surface area of cuticular membrane $\{\mathrm{CM}[\mathbf{A}$ (inset)] $\}$. Cell wall mass was calculated for ES of standard $0.5-\mathrm{mm}$ thickness. Maximum force $\left(F_{\max }\right)$ of ES was determined in uniaxial tensile tests as a function of cell wall mass per unit surface area $(\mathbf{B})$. Maximum force $\left(F_{\max }\right)$ of the $\mathrm{CM}$ as a function of CM mass per unit surface area $(\mathbf{B}$, inset). Values right of the dotted line (A) and left of the dotted line (B) represent samplings taken during cold storage. (C) Time course of change in maximum stress $\left(\sigma_{\max }\right)$ in the axial direction sustained by tissue cylinders $(15 \mathrm{~mm}$ diameter, $10 \mathrm{~mm}$ high) excised from the fruit flesh of 'Elstar' apple during cold storage $\left(1.7{ }^{\circ} \mathrm{C}, 92 \%\right.$ relative humidity). Time scale in $\mathbf{C}$ is in days after full bloom (DAFB). Fruit were harvested at $141 \mathrm{DAFB}$. The value are means $\pm \mathrm{sE}, \mathrm{n}=8$ to 12 .

subjected to the tensile tests. This "prestrain" may have contributed to the preharvest increase in $S$ and decrease in $\varepsilon_{\text {max }}$. The presence of such "prestrain" is inferred from the shape of the epidermal and hypodermal cells that changes from anticlinally elongated to periclinally elongated (Meyer, 1944). The decrease in $F_{\max }$ may also be a result of this strain. During expansion, the cell wall material is distributed over an enlarging area. The effect of this (unless a compensatory synthesis of cell wall material occurs) will be a decrease in the mass of cell wall material per unit of skin surface area (Fig. 7A). During the storage period, when surface expansion ceases, the observed decrease in $F_{\max }$ as fruit softened was most likely accounted for by an increase in the activity of cell-walldegrading enzymes (Fig. 7B). Furthermore, the decrease in slope of plots of $S$ or $F_{\max }$ vs. ES thickness (Figs. 2F-J and $4 \mathrm{~F}-\mathrm{J}$ ) was probably also related to the postharvest fruit softening (Fig. 7C).

Formation OF MICROCRACKS IN THE CM. The lower $\varepsilon_{\text {max }}$ of the CM compared with that of the ES causes the CM to fail when strained, long before the ES ruptures. This can be inferred from the appearance of microcracks in the CM of an ES subjected to a tensile force approaching $75 \%$ of its $F_{\max }$ (Fig. $6)$. The microcracks are highly oriented with a maximum incidence in a direction perpendicular to the applied force, which indicates a cause-and-effect relationship. Our observations are consistent with cuticular microcracks observed by SEM in the apple fruit surface (Curry, 2012; Faust and Shear, 1972b; Maguire et al., 1999; Roy et al., 1999). These microcracks are usually limited to the outer layers of the cuticle (Maguire et al., 1999) and do not extend deeply into the epidermal and hypodermal cell layers. As observed in the present study, they are often orientated in line with the anticlinal cell walls of groups of epidermal cells indicating that the pattern of the underlying cell walls affects the pattern of the cracks (Curry, 2012; Maguire et al., 1999). In fact, increased extensibility of the epidermal and, possibly, the hypodermal cell walls in the anticlinal regions might cause a concentration of the strain in these areas to produce this CM failure pattern (Maguire, 1998).

\section{Conclusions}

The fruit skin of a developing apple is subjected to continual growth strain in vivo. Because the $\varepsilon_{\max }$ exceeds the $\varepsilon_{\max }$ of the $\mathrm{CM}$ by almost an order of magnitude, failure of the polymeric CM precedes the failure of the cellular layers of the skin. As a result of the low $F_{\max }$ of the CM compared with that of the overall skin composite, the CM microcracking has a limited effect on the mechanical properties of the composite. This logic will not apply to the physiological consequences of an impairment of the CM's barrier properties. So long as the epidermal and hypodermal cells underlying the microcracks remain intact, continuing wax deposition in the CM microcracks will likely re-establish the skin's barrier function. This repair process is also referred to as the "stretching, shearing, and stitching mechanism" (Curry, 2009). When the rate of repair is insufficient and/or when the cracks extend more deeply into the underlying epidermal and/or hypodermal cell layers, we suggest that periderm formation is triggered by an as yet unknown mechanism causing the familiar symptoms referred to as russeting.

The findings presented in this article and the sequence of events outlined are consistent with the previously reported absence of significant relationships between the russeting susceptibilities of particular apple cultivars and the mechanical characteristics of their CM at maturity (Khanal et al., 2013a). Relationships between russet susceptibility and the rate of wax deposition and filling of cuticular cracks or russet susceptibility and the mechanical properties of epidermal and hypodermal cell layers would be more likely. In light of the economic importance of russeting and skin spot disorders, these topics merit more intense study. 


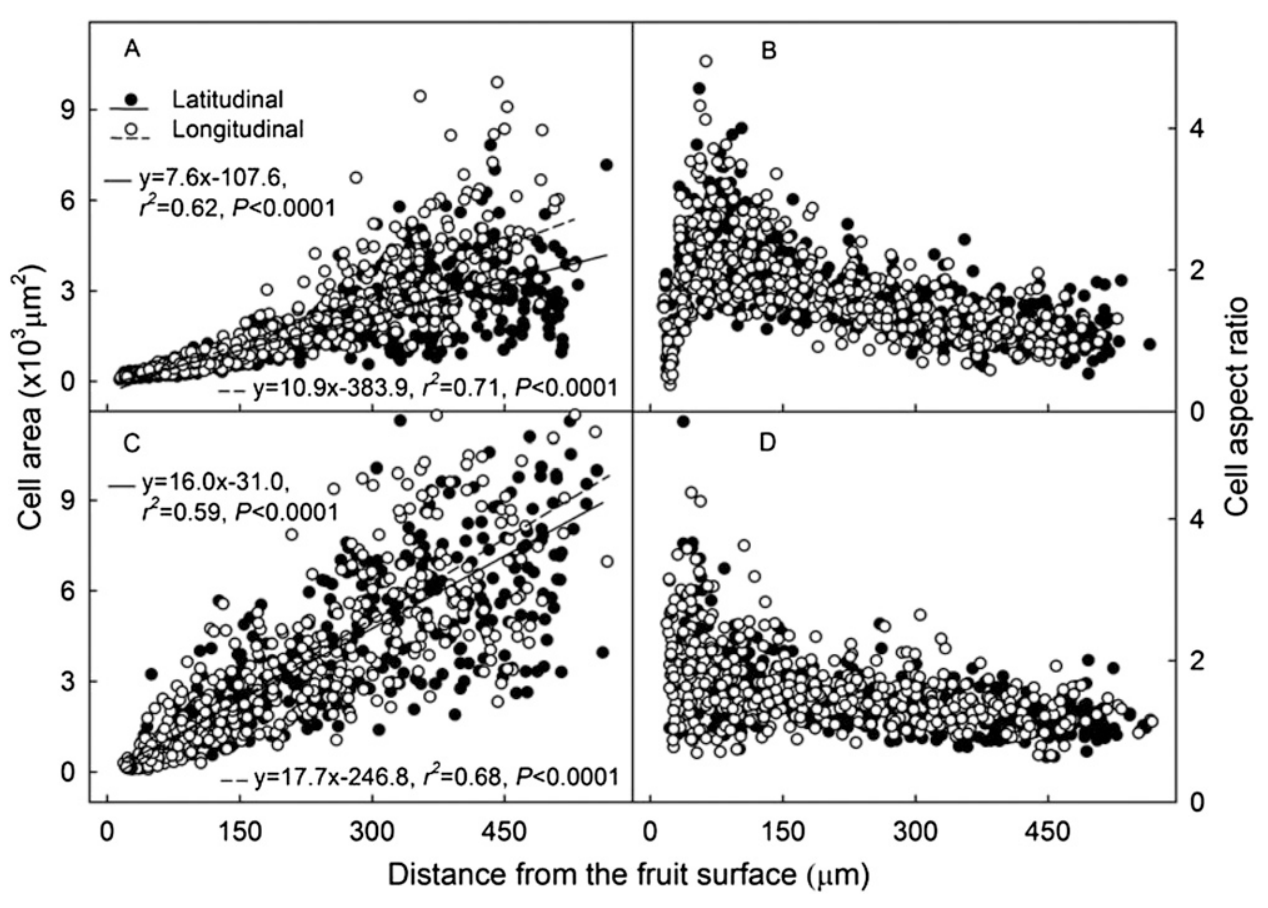

Fig. 8. Projected cross-sectional area $(\mathbf{A}, \mathbf{C})$ and aspect ratio (periclinal diameter/anticlinal diameter) $(\mathbf{B}, \mathbf{D})$ of the fruit skin cells of 'Elstar' apple at $51 \mathrm{~d}$ after full bloom (DAFB) (A-B) and at 141 DAFB (C-D) as a function of their depth below the skin surface. Data points represent individual cells.

\section{Literature Cited}

Chanliaud, E., K.M. Burrows, G. Jeronomidis, and M.J. Gidley. 2002. Mechanical properties of primary plant cell wall analogues. Planta 215:989-996.

Curry, E.A. 2009. Growth-induced microcracking and repair mechanism of fruit cuticles. Proc. Soc. Expt. Mechanics Annu. Conf. 23 Dec. 2013. <http://sem-proceedings.com/09s/sem.org-SEM-2009-AnnConf-s078p04-Growth-induced-Microcracking-Repair-MechanismsFruit-Cuticles.pdf $>$.

Curry, E.A. 2012. Increase in epidermal planar cell density accompanies decreased russeting of 'Golden Delicious' apples treated with gibberellin $\mathrm{A}_{4+7}$. HortScience 47:232-237.

Dominguez, E., J.A. Heredia-Guerrero, and A. Heredia. 2011a. The biophysical design of plant cuticles: An overview. New Phytol. 189:938-949.

Dominguez, E., J. Cuartero, and A. Heredia. 2011b. An overview on plant cuticle biomechanics. Plant Sci. 181:77-84

Evert, R.F. 2006. Esau's plant anatomy: Meristems, cells, and tissues of the plant body-Their structure, function, and development. 3rd Ed. Wiley, Hoboken, NJ.

Faust, M. and C.B. Shear. 1972a. Russeting of apples, an interpretive review. HortScience 7:233-235.

Faust, M. and C.B. Shear. 1972b. Fine structure of the fruit surface of three apple cultivars. J. Amer. Soc. Hort. Sci. 97:351-355.

Grimm, E., B.P. Khanal, A. Winkler, M. Knoche, and D. Köpcke. 2012a. Structural and physiological changes associated with the skin spot disorder in apple. Postharvest Biol. Technol. 64:111-118.

Grimm, E., S. Peschel, T. Becker, and M. Knoche. 2012b. Stress and strain in the sweet cherry skin. J. Amer. Soc. Hort. Sci. 137:383-390. Heredia, A. 2003. Biophysical and biochemical characteristics of cutin, a plant barrier biopolymer. Biochim. Biophys. Acta 1620:1-7. Jeffree, C.E. 1996. Structure and ontogeny of plant cuticles, p. 33-82. In: Kerstiens, G. (ed.). Plant cuticles: An integrated functional approach. Bios Scientific Publ., Oxford, UK.
Kerstiens, G. 1996. Cuticular water permeability and its physiological significance. J. Expt. Bot. 47:1813-1832.

Khanal, B.P., R. Shrestha, L. Hückstädt, and M. Knoche. 2013a. Russeting in apple seems unrelated to the mechanical properties of the cuticle at maturity. HortScience 48:1-4.

Khanal, B.P., E. Grimm, S. Finger, A. Blume, and M. Knoche. 2013b. Intracuticular wax fixes and restricts strain in leaf and fruit cuticles. New Phytol. 200:134-143.

Knoche, M., M. Beyer, S. Peschel, B. Oparlakov, and M.J. Bukovac. 2004. Changes in strain and deposition of cuticle in developing sweet cherry fruit. Physiol. Plant. 120:667-677.

Knoche, M., B.P. Khanal, and M. Stopar. 2011. Russeting and microcracking of 'Golden Delicious' apple fruit concomitantly decline due to gibberellin $\mathrm{A}_{4+7}$ application. J. Amer. Soc. Hort. Sci. 136:159-164.

Knoche, M. and S. Peschel. 2006. Water on the surface aggravates microscopic cracking of the sweet cherry fruit cuticle. J. Amer. Soc. Hort. Sci. 131: 192-200.

Lopez-Casado, G., A.J. Matas, E. Dominguez, J. Cuartero, and A. Heredia. 2007. Biomechanics of isolated tomato (Solanum lycopersicum L.) fruit cuticles: The role of the cutin matrix and polysaccharides. J. Expt. Bot. 58:3875-3883.

Maguire, K.M. 1998. Factors affecting mass loss of apples. PhD thesis, Massey Univ., Palmerston North, New Zealand.

Maguire, K.M., A. Lang, N.H. Banks, A. Hall, D. Hopcroft, and R. Bennett. 1999. Relationship between water vapour permeance of apples and micro-cracking of the cuticle. Postharvest Biol. Technol. 17:89-96.

Meyer, A. 1944. A study of the skin structure of 'Golden Delicious' apples. Proc. Amer. Soc. Hort. Sci. 45:105-110.

Miller, R.H. 1982. Apple fruit cuticles and the occurrence of pores and transcuticular canals. Ann. Bot. (Lond.) 50:355-371.

Orgell, W.H. 1955. The isolation of plant cuticle with pectic enzymes. Plant Physiol. 30:78-80.

Riederer, M. and L. Schreiber. 2001. Protecting against water loss: Analysis of the barrier properties of plant cuticles. J. Expt. Bot. 52:2023-2032.

Roy, S., W.S. Conway, A.E. Watada, C.E. Sams, E.F. Erbe, and W.P. Wergin. 1999. Changes in the ultrastructure of the epicuticular wax and postharvest calcium uptake in apples. HortScience 34:121-124.

Skene, D.S. 1982. The development of russet, rough russet and cracks on the fruit of the apple Cox's Orange Pippin during the course of the season. J. Hort. Sci. 57:165-174.

Tukey, H.B. and J.O. Young. 1942. Gross morphology and histology of developing fruit of the apple. Bot. Gaz. 104:3-25.

Vincent, J.F.V. 1990. Fracture properties of plant. Adv. Bot. Res. $17: 235-287$

Vincent, J.F.V. 1999. From cellulose to cell. J. Exp. Biol. 202:32633268 .

Wertheim, S.J. 1982. Fruit russeting in apple as affected by various gibberellins. J. Hort. Sci. 57:283-288.

Yamada, Y., S.H. Wittwer, and M.J. Bukovac. 1964. Penetration of ions through isolated cuticles. Plant Physiol. 39:28-32. 